\title{
Precocious and premature puberty associated with treatment of acute lymphoblastic leukaemia
}

\author{
A D LEIPER, ${ }^{*}$ R STANHOPE, $\dagger$ P KITCHING, ${ }^{*}$ AND J M CHESSELLS ${ }^{*}$ \\ ${ }^{*}$ Departments of Haematology and Oncology and + Growth and Development, Hospital for Sick Children, \\ London
}

SUMMARY Early puberty in 28 children (23 girls, five boys) treated for acute lymphoblastic leukaemia (ALL) at a mean age of 4.0 years (range $1.4-7 \cdot 8$ ) is described. All but one had received prophylactic cranial irradiation (1800-2400 cGy) and three children had received additional cranial or craniospinal irradiation as treatment for relapse of their leukaemia. Mean age for the onset of puberty was 8.8 (SD 0.8$)$ years in the girls and $9.3(0 \cdot 8)$ years in the boys; this is greater than two standard deviations from the mean for normal girls and boys. Five children (three girls, two boys) had precocious puberty. The onset of puberty occurred at greater than two standard deviations from the mean for normal girls and boys in $14(13 \%)$ girls and $4(3 \%)$ boys treated at less than eight years of age between 1970 and 1985. In a group of 55 girls treated for ALL who had survived in first remission for six years or more from diagnosis, there was a relation between young age at onset of treatment and early menarche. We suggest that premature activation of the hypothalamic-pituitary-gonadal axis occurs as a consequence of hypothalamic dysfunction due to cranial irradiation. Precocious and premature puberty in children treated for ALL may be an important factor in contributing to short stature.

The outcome for children with acute lymphoblastic leukaemia (ALL) has steadily improved since the introduction of combination chemotherapy and measures to prevent overt leukaemic infiltration of the central nervous system. ${ }^{1}$ The most common form of prophylaxis to prevent infiltration comprises fractionated cranial irradiation and a course of intrathecal methotrexate. Cranial irradiation commonly causes pituitary dysfunction when given in high doses for treatment of tumours of the central nervous system that are distant from the hypothalamic pituitary region. Growth hormone deficiency, ${ }^{2}$ delayed puberty, ${ }^{34}$ and precocious puberty ${ }^{56}$ have been reported. Endocrine morbidity in patients treated for acute ALL with cranial irradiation also occurs but to a lesser degree in those who have received $2400 \mathrm{cGy}$ or less. ${ }^{7}$ Partial or complete growth hormone deficiency is the commonest form of dysfunction and recently it has been recognised that its occurrence is far more widespread than previously suspected. ${ }^{28}$ Nevertheless, despite the recognition of growth impairment and deviation from expected height centiles in patients with acute ALL, ${ }^{9} 9$ most children receiving prophylaxis with cranial radiation have standing height measure- ments within the normal range and probably do not require growth hormone supplements. ${ }^{9}$ 10

We have recently noticed a tendency towards early pubertal development in female survivors of ALL treated with cranial irradiation. A similar finding has been reported by Pasqualini et al (Abstract presented at the Seventh International Congress of Endocrinology, October, 1984). We retrospectively analysed the timing and pattern of sexual maturation in children treated for ALL who presented to this hospital from 1970 to 1985.

\section{Patients and methods}

From 1970 to 1985 inclusive, 749 patients with ALL presented to this hospital; 482 were still alive in January 1987. Pubertal maturation was assessed in all current survivors who presented during this period and who were less than eight years old at the start of treatment, who had not received testicular or whole body irradiation, and whose present age was greater than 7 years. Two hundred and thirty three children conformed to these criteria. We analysed the data of 28 of these patients ( 23 girls, five boys) who had evidence of early ( $>1.4 \mathrm{SD})$ 
pubertal maturation. Twenty three were in first remission and five had one or more relapses. All had normal serum thyroxine and thyroid stimulating hormone concentrations at the time of assessment. One girl had a family history of early puberty. Mean age at initial treatment was 3.8 years (range, 1.4-6.5) in the girls and 4.8 years (range, $2 \cdot 6-7 \cdot 8$ ) in the boys.

Between 1970 and 1979 patients were treated on protocols that were divised by or being piloted for the Medical Research Council Working Party on Childhood Leukaemia; these have been described in detail elsewhere. ${ }^{1}$ From 1979 onwards patients were treated by protocols devised at the Hospital for Sick Children $^{11}$ or by the Medical Research Council Working Party (UKALL X). ${ }^{12}$ In 1972 cranial irradiation (2400 cGy in 15 fractions over three weeks) was introduced as prophylaxis against meningeal leukaemic infiltration in conjunction with a course of intrathecal methotrexate. From January 1981 onwards cranial irradiation was reduced to $1800 \mathrm{cGy}$ in 10 fractions over two weeks. One of the 28 patients, a girl diagnosed before 1972, did not receive cranial irradiation after induction but received craniospinal irradiation as treatment for a subsequent relapse in the central nervous system. Relapse and radiation data from the 28 patients compared with the total number of patients treated are shown in the table. Three patients, between 1970 and 1980, received 2000-2200 cGy.

Fifty five girls with ALL treated between 1971 and 1979 attained menarche. All were alive six years or more after diagnosis and had experienced no relapse of their leukaemia. The age at which menarche occurred was recorded in the case notes.

Height was measured with a stadiometer by standard anthropometric techniques. ${ }^{13}$ Puberty was staged by the method of Tanner. ${ }^{14}$ Testicular volume was assessed with an orchidometer. ${ }^{15}$ The attainment of stage 2 breast development in girls and a $4 \mathrm{ml}$ testicular volume in boys were used to indicate the onset of puberty. ${ }^{16}$ Normal data for the attainment of stages of sexual maturation and menarche were from Marshall and Tanner. ${ }^{17} 18$

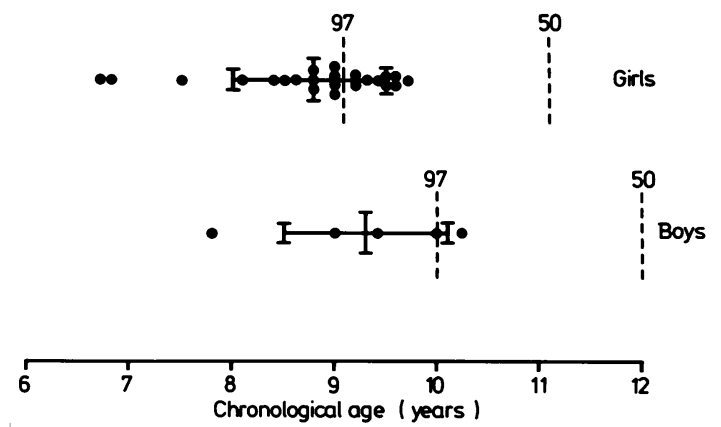

Fig 1 Age at onset of puberty of 28 children treated for $A L L$ at a mean age of 4.0 years (range $1 \cdot 4-7 \cdot 8$ ) compared with normal values. ${ }^{17} 18$ Mean age $(S D)$ of the onset of puberty in the 23 girls and five boys is shown. These patients were taken from a total of 233 (107 girls, 126 boys) treated at less than 8 years of age between 1970 and 1985.

Table Data of 28 children with evidence of early pubertal maturation

\begin{tabular}{|c|c|c|c|c|c|}
\hline & $\begin{array}{l}\text { Sex } \\
\text { of } \\
\text { child }\end{array}$ & $\begin{array}{l}\text { No with early } \\
\text { puberty } \\
\text { (total No }^{\text {assessed }}{ }^{*} \text { ) }\end{array}$ & $\begin{array}{l}\text { Type } \\
\text { of } \\
\text { relapse } \\
(n=5)\end{array}$ & $\begin{array}{l}\text { Radiation } \\
\text { dose } \\
(c G y)\end{array}$ & $\begin{array}{l}\text { Site } \\
\text { of } \\
\text { irradiation } \\
\text { (No of patients) }\end{array}$ \\
\hline & & 1970 & & & \\
\hline \multirow[t]{2}{*}{ First remission } & 15 girls & & & 2400 & Cranial (15) \\
\hline & 3 boys & $18(132)$ & & $2000-2200$ & Cranial (3) \\
\hline \multirow[t]{2}{*}{ Relapses } & 4 girls & $4(21)$ & Bone marrow & 2400 & Cranial (2) \\
\hline & & & (4) & $\left\{\begin{array}{l}2400+ \\
1800\end{array}\right.$ & Cranial (2) \\
\hline \multirow[t]{2}{*}{ Total } & & $22(153)$ & & & \\
\hline & & 1981 & & & \\
\hline \multirow[t]{2}{*}{ First remission } & 3 girls & & & 2400 & Cranial (1) \\
\hline & 2 boys & $5(72)$ & & 1800 & Cranial (4) \\
\hline Relapses & 1 girl & $1(8)$ & $\begin{array}{l}\text { Central nervous } \\
\text { system }\end{array}$ & $\left\{\begin{array}{l}1800+ \\
2400\end{array}\right.$ & $\left\{\begin{array}{l}\text { Cranial, } \\
\text { craniospiral (1) }\end{array}\right.$ \\
\hline Total & & $6(80)$ & & & \\
\hline
\end{tabular}

${ }^{*}$ Less than 8 years old at start of treatment. 
Fourteen patients (11 girls, three boys) had computed tomograms taken of the brain by either a Toshiba TCT 60 scanner with hypothalamic pituitary reconstructions or an EMI scanner. Mean timing of the first scan from the onset of prophylactic central nervous system irradiation was 2.75 years (range $0 \cdot 1-11 \cdot 0$ ); five patients had brain scans before one year from the onset of central nervous system irradiation. Nine patients had serial computed tomograms taken, up to a maximum of four scans.

\section{Results}

Fig 1 shows the age of onset of puberty in the 28 patients compared with data from normal children; three girls and two boys had precocious puberty (signs of sexual maturation occurring before 8 years in girls and 9 years in boys. ${ }^{19}$ Mean age for the onset of puberty was $8.8(\mathrm{SD} 0.8)$ years in the girls and 9.3 $(0 \cdot 8)$ years in the boys. Mean age for the onset of puberty in these 28 patients was greater than two standard deviations from the mean for normal girls ${ }^{17}$

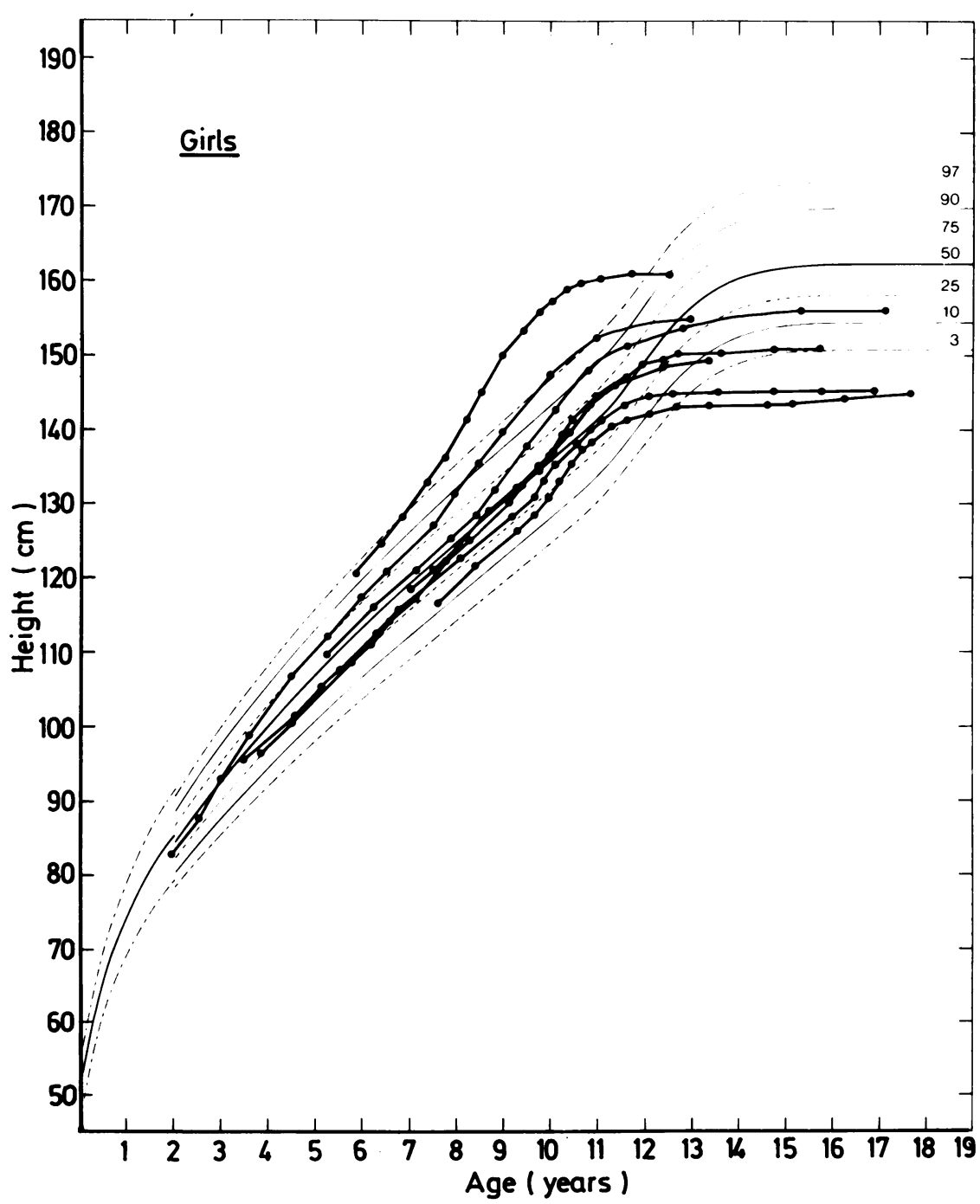

Fig 2 Growth data from seven girls treated for ALL whose growth had been, or almost been, completed. None had received spinal irradiation. Onset of the growth spurt is compared with normal values for British children. ${ }^{20}$ 
and boys. ${ }^{18}$ The onset of puberty in patients treated during the years 1970-80 occurred at more than two standard deviations from the mean for normal girls and boys in 10 girls $(14 \%)$ and three boys $(4 \%)$. The onset of puberty in patients treated during the years 1981-5 occurred at more than two standard deviations from the mean for normal girls and boys in four girls $(12 \%)$ and one boy $(2 \%)$. In both treatment periods, $1970-80$ and $1981-85$, the number of girls entering puberty before two standard deviations from the mean was much greater than the $3 \%$ one would have expected in the normal population. Equivalent data for the boys were not significant. The ratio of girls to boys entering puberty at more than two standard deviations from the mean was $4: 1$. Unfortunately we do not have data on the timing of the onset of puberty in all patients included in this study. The onset of puberty was only accurately assessed when early sexual maturation was noticed and so our figures probably underestimate the true incidence of early puberty.

Fig 2 shows the growth of seven girls from this

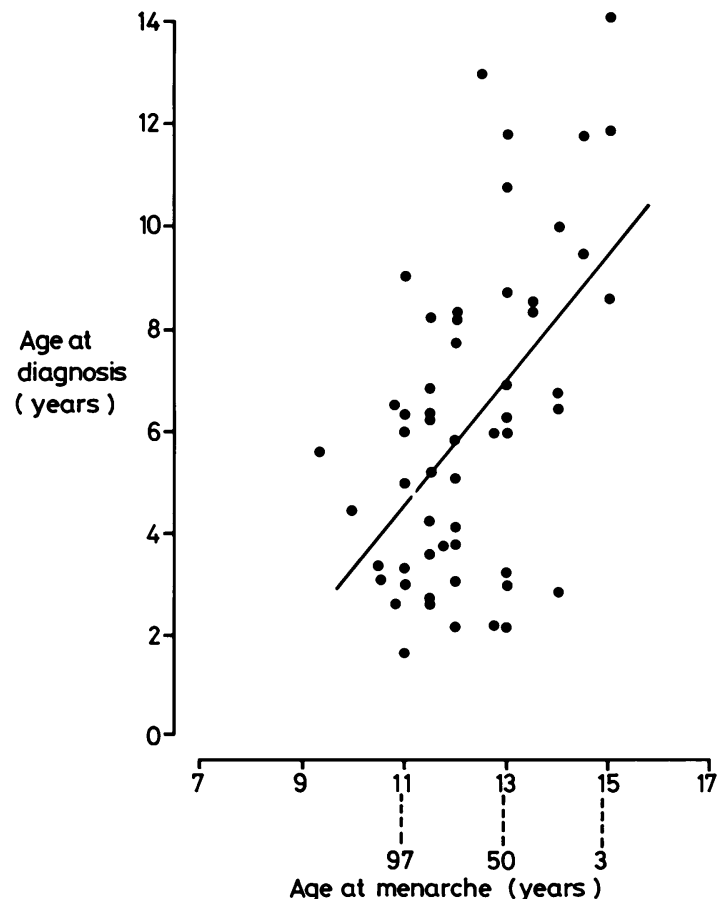

Fig 3 Data of age at diagnosis (equivalent to age at start of treatment) and age at menarche from 55 girls with ALL, treated between 1970 and 1979 who were alive six years or more from diagnosis in first remission. All had received prophylaxis with cranial irradiation (2400 cGy; $r=0.53, p<0 \cdot 001)$. Normal data for menarche are shown. ${ }^{17}$ group where final height had been, or had almost been, achieved. The early onset of the growth acceleration can be seen when compared with the normal of Tanner et al. ${ }^{20}$ Four patients had final heights equal to or less than the third centile but their growth hormone state and epiphyseal maturation had not been assessed, and no conclusion can be drawn from these data about the effect of early puberty on growth prognosis.

None of the computed tomograms showed evidence of hydrocephalus, and the ventricular size in patients who had serial scans did not change. One girl had diffuse cerebral changes that were probably due to methotrexate encephalopathy. Another girl had an empty sella; this has been associated with irradiation damage. $^{21}$

Data relating age of onset of treatment of 55 girls with age at menarche are shown in fig 3 . The younger the age at diagnosis (equivalent to age at the start of treatement) the earlier menarche occurred $(\mathrm{r}=0.53, \mathrm{p}<0.001)$.

\section{Discussion}

Our data suggest that treatment of ALL is associated with the development of premature puberty, and, in a significant proportion of children, precocious puberty. Our patients retained the harmony of the sequence of acquisition of secondary sexual characteristics and the relation of these to the growth spurt that is characteristic of normal puberty. ${ }^{22}$ Therefore, premature and precocious puberty in our patients was likely to be central (gonadotrophin dependent) in origin, although we do not have endocrinological data. The onset of pubertal development was related to the age of onset of treatment. This parallels the finding that young children are more susceptible to growth hormone insufficiency after prophylaxis with cranial irradiation in the treatment of ALL. ${ }^{23}$

Cranial irradiation has been reported to cause central precocious puberty in both the treatment of brain tumours in doses greater than $3300 \mathrm{cGy}$ and in one girl with ALL when the dose of irradiation was only $2400 \mathrm{cGy}^{6}$; this girl, however, also received intrathecal methotrexate. In our patients premature puberty was associated with doses of cranial irradiation as low as $1800 \mathrm{cGy}$. The incidence of early puberty was slightly higher in the group of patients diagnosed between 1970 and 1980 . This is likely to reflect the greater proportion of children of adolescent age, but the lower dosage of $1800 \mathrm{cGy}$ of cranial irradiation introduced in 1981 may also have bearing on this observation. Only greater numbers and a longer follow up will elucidate this further. Damage to the hypothalamic-pituitary axis can 
cause abnormal secretion of gonadotrophin releasing hormone and be associated with either precocious or delayed puberty. ${ }^{3}$ The change in hypothalamic function that we have seen was probably caused by irradiation rather than intrathecal chemotherapy and like other endocrine effects of irradiation seems to have been delayed. ${ }^{2}$ We found no evidence of hydrocephalus occurring as a consequence of cranial irradiation in the regimen that we used.

There was a four fold preponderance of girls with early puberty that was not accounted for by superior survival of girls over boys. In this study, when all criteria for inclusion were met, there were roughly equal numbers of boys and girls. There is a sex difference in the response to gonadotrophin releasing hormone and its analogues that may be relevant to this observation. In delayed puberty induced by pulsatile administration of gonadotrophin releasing hormone girls require lower doses than boys to maintain equivalent progress in sexual maturation. ${ }^{24}$ By contrast, in the suppression of central precocious puberty, girls require larger doses of gonadotrophin releasing hormone analogue than boys. ${ }^{25}$

The growth of children with central precocious puberty is compromised by rapid epiphyseal maturation that ultimately limits growth. ${ }^{19}$ It may well be that premature puberty, such as we have described, may cause a similar phenomenon. There are many other factors, however, such as growth hormone insufficiency, which are pertinent to the growth of children with treated ALL especially those who have been retreated after a relapse. ${ }^{2}$ The impairment in growth caused by growth hormone insufficiency or spinal irradiation, or both, is probably masked by the early growth spurt associated with precocious or premature puberty. The net result would be a relatively normal growth velocity but with rapid advancement in epiphyseal maturation causing a reduction in adult height potential. Without regular anthropometric measurements, including sitting height and accurate assessment of epiphyseal maturation, such an effect on growth could be misinterpreted.

We believe that the recognition of premature sexual development in children with ALL may be important both for psychological and anthropometric reasons. Although cyproterone acetate ${ }^{26}$ and probably gonadotrophin releasing hormone ana$\operatorname{logues}^{27}$ do not affect the final prediction of height of children with central precocious puberty, both agents suppress sexual maturation. We agree with the suggestion of Brauner and Rappaport ${ }^{\mathrm{t}}$ that a combined approach with a gonadotrophin releasing hormone analogue and human growth hormone may therefore provide the best anthropometric response.
Shalet has dicussed the role of endocrine deficiency and spinal growth in the impairment of the growth of children with treated ALL. ${ }^{28}$ We wish to add to the list premature and precocious puberty as important additional sequelae.

We are grateful to Professor MA Prece, Institute of Child Health, London, for his helpful criticism of the manuscript.

\section{References}

' Chessells JM, Ninane J, Tiedemann K. Present problems in management of childhood lymphoblastic leukaemia. Experience from the Hospital for Sick Children, London. In: Neth $R$, Gallo RC, Graaf T, Mannwcilcr R, eds. Modern trends in human leukaemia. Berlin: Springer-Verlag, 1981:108-14.

2 Shalet SM. Irradiation-induced growth failure. Clin Endocrinol Metab 1986;15:591-606

3 Styne DM. Grumbach MM. Puberty in the male and female: its physiology and disorders. In: Yen SSC, Jaff RB, eds. Reproductive endocrinology. Philadelphia: WB Saunders, 1976:189-240.

4 Rappaport R, Brauner R. Czcrnichow P, et al. Effect of hypothalamic and pituitary irradiation on pubertal development in children with cranial tumours. J Clin Endocrinol Metab 1982;54:1164-8.

s Brauner R, Czernichow P, Rappaport R. Precocious puberty after hypothalamic and pituitary irradiation in young children. $N$ Engl J Med 1984;311:920.

${ }^{6}$ Brauner R, Rappaport R. Precocious puberty secondary to cranial irradiation for tumours distant from the hypothalamopituitary area. Horm Res 1985;22:78-82.

${ }^{7}$ Shalet SM, Beardwell CG, Twomey JA. Morris Jones PH, Pearson D. Endocrine function following the treatment of acute leukacmia in childhood. J Pediatr 1977;90:920-3.

${ }^{*}$ Kirk JA, Raghupathy P. Stevens MM, et al. Growth failure and growth hormone deficiency after treatment for acute lymphoblastic leukacmia. Lancet 1987;i:190()-3.

${ }^{9}$ Robison LL, Nesbit ME, Sather HN, Meadows AT Ortega JA, Denmond Hammond G. Height of children successfully treated for acute lymphoblastic lcukacmia: a report from the late effects study committec of children's cancer study group. Med Pediatr Oncol 1985;13:14-21.

10 Wheeler K. Leiper AD, Janoun L. Chessells JM. Childhood acute lymphoblastic leukacmia: the medical cost of cure Br Med J 1987 (in press)

$"$ Chessells JM, Leiper AD, Tiedemann K, Hardisty RM. Oral methotrexate is as effective as intramuscular methotrexate in maintenance therapy of acute lymphoblastic leukaemia. Arch Dis Child 1987;62:172-6.

12 Pinkerton CR, Bowman A, Holzel H, Chessells JM. Intensive consolidation chemotherapy for acute lymphoblastic leukacmia (UKALL X pilot study). Arch Dis Child 1987:62:12-8.

13 Brook CGD. Growth assessment in childhood and adolescence. Oxford: Blackwell Scientific Publications, 1982.

14 Tanner JM. Growth at Adolescence. 2nd ed. Oxford: Blackwell Scientific Publications, 1962.

15 Zachmann M. Prader A, Kind HP. Haflinger H, Budlinger $H$. Testicular volumes during adolescence. Cross-sectional and longitudinal studies. Helv Paediatr Acta 1974:29:61-72.

16 Winter JSD, Faiman C. Pituitary gonadal relationships in male children and adolescents. Pediatr Res 1972;6:126-35.

17 Marshall WA. Tanner JM. Variation in the pattern of pubertal changes in girls. Arch Dis Child 1969:44:291-303.

${ }^{18}$ Marshall WA. Tanner JM. Variation in the pattern of pubertal changes in boys. Arch Dis Child 1970);45:13-23.

${ }_{19}$ Rayner PHW. Early puberty. In: Brook CGD, ed. Clinical paediatric endocrinology. Oxford: Blackwell, 1981:224-39.

20) Tanner JM, Whitchouse RH, Takaishi M. Standards from birth to maturity for height, weight, height velocity and weight 
1112 Leiper, Stanhope, Kitching, and Chessells

velocity: British children, 1965. Arch Dis Child 1966;41:454-71, 613-35.

${ }^{21}$ Stanhope R, Adlard P. Empty sella syndrome. Dev Med Child Neurol 1987;29:397-9.

22 Stanhope R, Brook CGD. The clinical diagnosis of disorders of puberty: the loss of consonance. Br J Hosp Med 1986;35:57-8.

23 Brauner R, Czernichow P. Rappaport R. Greater susceptibility to hypothalamo-pituitary irradiation in younger children with acute lymphoblastic leukacmia. J Pediatr 1986;108:332.

${ }^{24}$ Stanhope R, Adams J, Brook CGD. Disturbances of puberty. Clin Obstet Gynecol 1985:12:557-77.

${ }^{25}$ Donaldson MDC, Stanhope R, Lee TJ, Price DA, Brook CGD. Savage DCL. Gonadotrophin responses to $\mathrm{GnRH}$ in precocious puberty treated with $\mathrm{GnRH}$ analogue. Clin Endocrinol 1984;21:499-503.
26 Werder EA, Murset E, Zachmann M, Brook CGD. Prader A. Treatment of precocious puberty with cyproterone acetate. Pediatr Res 1974:8:248-56.

27 Werder EA, Illig R, Zachmann M, Torresani T, Prader A. Treatment of precocious puberty in girls with intranasal LHRH agonist (buserelin). Pediatr Res 1986;20:1185.

$2 x$ Shalet SM. The effects of cancer treatment on growth and sexual development. In: Aynsley-Green A, ed. Paediatric endocrinology in clinical practice. Lancaster: MTP press, 1984:183-99.

Correspondence to Dr R Stanhope, Department of Growth and Development, Institute of Child Health, 30 Guilford Street, London WCIN $1 \mathrm{EH}$.

Received 29 June 1987 